\title{
On the Interactive Influence of College Students' Network Behaviors and Actual Personality
}

\author{
Bo Wei \\ Zhuhai College of Jilin University \\ Zhuhai, Guangdong, China
}

\author{
Feng Tian \\ Zhuhai College of Jilin University \\ Zhuhai, Guangdong, China
}

\author{
Dongfu Ji \\ Zhuhai College of Jilin University \\ Zhuhai, Guangdong, China
}

\begin{abstract}
To a very large extent, college students' network behaviors, which are a kind of satisfaction of their actual psychological needs, form an interactive influence with actual personality. The failure to reach consistency between the "virtual me" on the Internet and the "actual me" in reality will probably lead to defects to the actual personality of these college students. Reinforcing the research on the interaction between network behaviors and actual personality is advantageous to adolescent college students' perfection of their actual personality during their growth and the process of becoming excellent.
\end{abstract}

Keywords-college student; network behavior; actual personality; interactive influence

\section{INTRODUCTION}

The convenience and benefits brought by the network are obvious to us all. By virtue of the network, college students can learn knowledge and grasp skills, and keep a close watch on politics, current events and hot topics in the society. More importantly, as we media becomes vigorous, they have more opportunities to participate in and organize activities to express and demonstrate themselves. They prefer to reveal their emotions and viewpoints, and forward and re-post words that inspire them, and photos and events that show up in their we media can touch them more easily. However, while they are indulging themselves to the fruits brought by the civilization of modern technology, puzzles generated by the network have gradually emerged and aggravated. Phenomena like the failure to reach consistency between the "virtual me" on the Internet and the "actual me" in reality, the excessive expansion of selfawareness and conformity on the Internet, as well as the addiction to the network have been found among the netizens. Everybody can play the role as an observer, commenter, participator, organizer and media worker via the Internet. College students are an important group and the most active group among netizens. At the stage in which their outlook of the world, life and value is being formed and fixed, college students will accept novelties and be misled by them more easily. Network brings people an experience that's superior to a certain stage of their life or an unprecedented experience in

Foundation: Cultivation of College Students' Network Personality Based on Organizational Behavior, (No.: 2015DYYB079), key project of 2015 Guangdong School Moral Education Innovation, presided over by: Weibo. the real society, which will easily lead to self-deviation.

Personality is spiritual guidance of actual behavior, which is also a reflection of the former. Network behavior is an extension and expansion of actual behavior via the Internet. An interactive influence exists between network behavior and actual personality, and sound actual personality can regulate network behavior, or vice versa; unsound network behavior will also be reflected in actual personality and influence its soundness. Only when network behavior and actual personality reach consistency can individual's sound development be facilitated.

\section{COLLEGE STUdENTS’ NeTwORK BEHAVIORS AND MOTIVES}

In the questionnaire survey on college students' network behaviors, students of Department of Chinese Language and Literature, Zhuhai College of Jilin University are included as the respondents. A total of 315 valid questionnaires were collected. According to $26.27 \%$ students, they cannot be separated from the network, $33.54 \%$ students have forwarded information without any discrimination. Meanwhile, only a quarter of students believe their network behaviors are consistent with their actual behaviors.

\section{A. Five Main Expressions of College Students' Network Behaviors}

In the above-mentioned questionnaire survey, it is found that college students hold different objectives and motives when utilizing the network. However, their behaviors can mainly be summarized in the following aspects. The first one is knowledge learning and information gathering. Some college students learn and strengthen their specialized knowledge through the Internet. They are not strongly dependent on the network, and the time they spend on surfing the Internet is short. During the survey, it is found that college students will basically utilize the network for learning, but there's only a small proportion of students who can enduringly, intensively and meticulously utilize it for their study. Most students utilize the network for studying temporarily, such as during paper writing and reviewing for tests. The second one is 
interpersonal communication and social interaction. In the questionnaire, basically all the college students utilize the network to develop their interpersonal relationship, and WeChat, Microblog and QQ are the most commonly utilized and most preferred tool. With these modes of communication, they seldom utilize the traditional telephone, short message or even face-to-face communication. And some college students even show a high level of dependence on the new modes of communication. Moreover, college students also stick to the upgrade of the carrier of online communication. The third one is the needs for entertainment. Computer, tablet computer and mobile phone are the necessities in their life. These are also an important carrier of college students' recreational life. At anytime and anywhere, they utilize these tools to spend hours on watching TV plays, live programs and news reports, and playing online games, etc. The fourth one is Internet consumption, which is a decisive link in college students' elife. Online food ordering, shopping, virtual commodities and game recharging are the content of their online consumption. The fifth one is online entrepreneurship. Online marketing, purchasing agent, opening of public account and app designing are the several forms of college students' Internet entrepreneurship.

College students satisfy their demands in all the aspects by thoroughly utilizing the network, and depend on the network to develop themselves to different degrees. By virtue of the network, they study online, express themselves and communicate with others, and satisfy their demands for entertainment and online consumption, and they even start their own business to realize their dream. It's not difficult to find that the proportion of college students who have the network behaviors of studying and starting their own business is quite limited. And interpersonal communication, entertainment and online consumption are the network behaviors that actually occupy most of their time.

\section{B. Five Motives of Utilizing the Network under "Maslow's Demand"}

In their research, the two researchers Zhourong and Zhouqian discussed five pleasant sensations of communication generated by netizens from the perspective of "rate and pleasure of spreading", and they are: the pleasant sensation of being anonymous, conducting interpersonal interaction, behaving, interacting with texts and avoiding. According to them, the sense of satisfaction brought by the network reflects people's psychological and physiological dependency to a certain extent. From Maslow's theory of five hierarchies of demand, the motives held by college students during the Internet-surfing are analyzed. It is believed by Maslow's hierarchy of needs that human beings' behaviors and needs can be divided into five types from the bottom to the top like the staircase, and these five types are physiological needs, security needs, social needs, and the needs of self-esteem and selfactualization. We can see from college students' network behaviors that other than satisfying their basic demand of studying, college students surf the Internet to realize interpersonal communication, interaction in a virtual community, and the demand for entertainment and online shopping. Most of the time, they hold the objective of pursuing entertainment, social interaction and time-killing, rather than such objective and motive as information-seeking. Firstly, physiological needs. College students' utilization of the network to purchase and even browse some pornographic content is an expression of their physiological needs. Secondly, security needs. In a virtual community like the network, netizens will build a sense of superiority and an unknown pleasant sensation from others' compliment, and will even conduct a behavior of avoiding responsibility unconsciously. Thirdly, social needs. In the interpersonal communication via the network, college students can conceal their weaknesses, such as the poor ability and skills of conversation and social contact, and satisfy their needs of communicating, sharing and making friends with others. Fourthly, needs of self-esteem. In the virtual network, it's unnecessary to have face-to-face communication with others. Without knowing each other very deeply, they can demonstrate themselves willingly and win others' compliment and respect. Fifthly, needs of selfactualization. By learning and starting business via the network, college students can create conditions and accumulate information for self-actualization.

College students' various behaviors during the Internetsurfing are a demand of seeking for self-satisfaction, searching information, reinforcing interaction with the society and avoiding the reality. Severe Internet and game addicts are all dependent on the network. It's difficult for them to control their dependency on the network and their psychological demands need to be adjusted properly. As a whole, no matter which aspect the researchers choose as the entry point to summarize college students' motives of Internet-surfing, it can all be described as a reflection of college students' physiological and psychological demands.

\section{THE RELATIONSHIP BETWEEN COLLEGE STUDENTS' NETWORK BEHAVIORS AND ACTUAL PERSONALITY}

With the development and popularization of the network, especially the development of small-screen and 4G network technology, our acquisition of information becomes more convenient and relaxing. However, some people who are very traditional, steady and rational in practical life, can be very fashionable, aggressive and emotional on the Internet. The inconsistency and separation will easily make them lose themselves on the Internet. As a result, they will easily play the role as a certifier and referee, and become perplexed about illusions on the Internet. They will have difficulty identifying themselves, and will easily be stuck in a wrong path. In his Master's dissertation On the Relationships among 286 College Students' Internet-surfing Behaviors, Motives and Personality, Tan Wenfang elaborates the relationship between college students' Internet-surfing behaviors and actual personality. He mainly expounds the differences among the introverted, extroverted and ambiverts in the time they spend on surfing the Internet. "The Big Five" personality model (openness to experience, agreeableness, conscientiousness, neuroticism and extraversion) is mainly taken as a reference in this paper. Furthermore, the relationship between actual personality and network behaviors is elaborated both positively and negatively.

- Positively speaking, sound personality drives and guides college students' network behaviors; 
meanwhile, appropriate network behaviors reinforce college students' actual personality. People with sound personality can discipline themselves and understand how to control their behaviors. In terms of emotiondirected behaviors, they manifest the characteristics of positive, forward-looking and self-motivated. The network behaviors of college students who hold different personalities are not the same. Let's take the personality of conscientiousness as an example. It means we know how to discipline and control ourselves. On the top of the dimension, people are well-organized and perseverant; on the bottom of the dimension, people are careless, inconstant and unreliable. It is found through the survey that some college students can effectively utilize the network to enrich and develop themselves, such as learning and starting business. These students are mostly on the top of the dimension in terms of conscientiousness. More students show an inclination of wasting time browsing news and clicking to watch different contents that pop out. These students are mostly on the bottom or the medium part of the dimension. Meanwhile, appropriate network behaviors can reinforce the actual personality. Nowadays, the content of network is overwhelmingly abundant, and the information manifests geometric growth. Provided that we cannot hold an open attitude and enrich ourselves timely and effectively with the network, we will fall behind others. In terms of personality, this phenomenon can be described with "openness". Those who obtain high score do not stick to the convention, and they think independently; those who obtain low score are relatively traditional, and they would rather choose familiar objects than novelties. Searching information and new knowledge with the Internet can promote our acceptance towards novelties.

- Negative speaking, unsound personality will easily lead to rebellious network behaviors among the college students; meanwhile, excessive network behaviors will weaken college students' perfection of their actual personality. In the practical society, we would find many phenomena, such as the smartphone addicts, network addicts, cyber pornography and violence in the small-screen era. Some college students indulge themselves to virtual roles on the Internet, such as virtual marriage and vegetablestealing in online games, which cause a chaos of their own roles in reality. If college students utilize the network excessively or inappropriately, they will be prevented from sound physical and mental development, be separated from the practical society, and even be forced to give up their regular activities, for example, study. College students who are addicted to online games and are excessively fond of online chatting are mostly self-centered and introverted in real life, and they are not adept in interpersonal communication. From the analysis of extraversion in "The Big Five" personalities, this kind of students shows an inclination towards both sides of extraversion---the dimension of extreme introversion.
In addition, their network behaviors will further weaken the perfection of their actual personality, prevent them from interacting with the society, and even trigger illegal behaviors in reality.

IV. SugGestions of Optimizing College Students' NETWORK BEHAVIOR, AND PROMOTING THE PERFECTION OF ACTUAL PERSONALITY

The influential factors of the formation of personality can be in different aspects. There are biological, social, cultural and family factors. At the stage of forming and perfecting personality, college students should figure out feasible methods to facilitate the optimization of network behaviors and perfection of their personality.

\section{A. Clean the Network}

Network is one of the indispensable tools in modern life. By virtue of the network, college students can satisfy their demands for material and spiritual life, and they spend many hours surfing the Internet. In the era in which everybody is a provider of network information, there's an overwhelming amount of information that's quite difficult to distinguish. This will probably mislead netizens, especially college students, whose accumulation of knowledge is insufficient and ability of discrimination still needs further improvement. Consequently, there are disordered behaviors during the utilization of network. Hence, in the sufficient network information, we should clean the network and enhance the quality of the content. Particularly, we should govern false information and Internet rumors without any delay.

\section{B. Reinforce and Enrich the Content and Form of College Teaching}

College students are fond of the Internet, with which, they search information and solve problems. Although such forms as online teaching, micro-class and Massive Open Online Courses (MOOC) have been quite popular for the time being, we are still far from the era, in which online teaching plays a dominant role in college students' learning. And offline teaching still occupies that role. Under the circumstance, an optimal method of attracting college students to transfer their focus from the online to the offline platform is to reinforce and enrich college teaching in content and form. The content should be integrated with the practical situation, be not confined to theories, and satisfy different college students' appeal for knowledge learning. The form should be high-end, magnificent and classy, and not be confined to classroom teaching. Meanwhile, an emphasis should be placed on the practice.

\section{Strengthen the Cultivation of College Students' Actual Personality}

A project focused on personality cultivation has been launched throughout Shandong University in 2012. It raises personality cultivation to another height. College students' actual personality and network behaviors are mutually influenced. Sound personality guides and helps college students to be able to regulate network behaviors, and 
promotes college students to correctly cognize the role of the network. The formation and perfection of personality cannot be accomplished one day. During this process, there are many influential factors. It's possible that physiology, family and the society will exert influence on the formation and transformation of personality. Hence, we should help college students perfect their personality from the perspective of family, school and the society with consistent understanding, explicit objectives and divided responsibilities.

\section{Guide Public Opinion, Help College Students Correctly Cognize the Network}

Correct understanding of the advantages and disadvantages of the network will help college students regulate their network behaviors and reasonably utilize the network. College students are in the stage, where their mind is extremely active, their outlook of value is being formed and discriminability needs further improvement. College students who are passionate, energetic and impulsive, will easily be "kidnapped" by some hot events on the Internet. There's a possibility that college students will be attracted by verbal violence and moral kidnapping on the Internet. Correctly guiding public opinion and helping college students build correct cognition of network events, and the advantages and disadvantages of the network will facilitate college students in the formation of a correct outlook of value, and help them reduce deviations during the perfection of personality.

In conclusion, the interactive influence of college students' network behaviors and actual personality can be positive and negative. Thoroughly exerting the positive influence can be advantageous to not only college students' regulation of network behaviors, but also their perfection of actual personality, and their sound development.

\section{REFERENCES}

[1] Tan Wenfang. On the Relationships among 286 College Students' Internet-surfing Behaviors, Motives and Personality [D]. Changsha: Hunan Normal University, 2003.

[2] Li Peifen, Liao Chuanjing. Survey on College Students' Network Behaviors and the Influence on Sound Personality [J]. Academic journal of Inner Mongolia Normal University (Education Science Version), 2008, 21(1): 67-71

[3] Wu Yian. On the Regulation of Contemporary College Students' Network Behaviors [D]. Xi'an: Xi'an University of Science and Technology, 2013.

[4] Wan Xiaoxia. On the Relationships among College Students' Network Behaviors, Personality Characteristics and Self-congruence [J]. Chinese Mental Health Journal, 2009, (4): 299-300 